\title{
W. J. Brogden: The experimentalist
}

\author{
DAVID A. GRANT \\ University of Wisconsin-Madison, Madison, Wisconsin 53706
}

Wilfred John Brogden was one of the founders of the Psychonomic Society. A charter member, Wulf served on the first Governing Board, being its third Chairman. He arranged for the incorporation of the society and he supervised the steps required to obtain its tax-exempt status. The nature of the Psychonomic Society reflects Wulf's scientific nature, and Wulf's activities on its behalf were very characteristic of the man. He was interested in psychology primarily as a science. Seeing the future of scientific psychology with unusual wisdom and clarity, he was a careful planner of institutional policy, and he was singularly effective in handling administrative tasks that were required to launch the Society in such a way as to achieve the goals originally set for it.

Just as Cliff Morgan's characterization of S. S. Stevens as "The Psychophysicist" was singularly apt, I believe that Wulf Brogden can very appropriately be characterized as "The Experimentalist"- thus the title of this address.

\section{A CAREER SYNOPSIS}

Wulf Brogden was born in Sydney, Australia, on May 6, 1912, the first son of John Brogden, a Unitarian minister, and Elsie May Brogden. He entered the United States with his parents and one younger brother in August 1914, and he became a raturalized citizen through the naturalization of his father in 1926. Obtaining his secondary education in Hanilton, Ohio, and Dallas, Texas, he entered Southern Methodist. University in 1929 and subsequently transferred to the University of Illinois, where he earned his BA degree with a psychology major in February 1933. Brogden then entered graduate study in psychology at the University immediately on being graduated, and he received his $\mathrm{PhD}$ in 1936 with a major in experimental psychology and minors in physiology and chemistry. His doctoral dissertation, "Increased auditory acuity in dogs

This address was presented at the meeting of the Psychonomic Society in Boston. November 21, 1974. The author wishes to thank those who assisted him in verifying or correcting much of the information presented in this paper. In particular, he should mention three of Brogden's PhDs, W. F. Battig, R. F. Thompson, and J. F. Voss, and three of his fellow students at Illinois, H. W. Ades, G. Finch, and E. Girden. following roentgen radiation of the pituitary body," utilized psychophysical and motor conditioning methods which he had helped to develop in the Animal Hearing Laboratory that was founded and directed by Professor Elmer Culler. Motor conditioning and psychophysics continued to be topical areas to which many of Brogden's subsequent research efforts were directed. After receiving his $\mathrm{PhD}$ degree, Dr. Brogden spent 3 years at the Pavlovian Laboratory of the Phipps Psychiatric Clinic of the Johns Hopkins School of Medicine, which was directed by Dr. W. Horsley Gantt. The 3 years with Culler and the 3 years with Gantt established a pattern of research activity which was to characterize his whole professional career. By the time of his appointment in 1939 as Assistant Professor of Psychology at the University of Wisconsin, he had published 10 scientific papers. Ten of his early papers were cited in Hilgard and Marquis' 1940 classic, Conditioning and Learning, and examination of these papers with the relevant textual material in "Hilgard and Marquis" reveals that Brogden's research had dealt with important scientific issues and was already beginning to have a significant scientific impact.

Although he taught at the University of Rochester and at Harvard University during the summers of 1942 and 1946, respectively, and was placed on leave of absence from 1942 to 1945 in order that he might engage in research connected with World War II, Professor Brogden held academic appointments at the University of Wisconsin from 1939 until his death. He was promoted to Associate Professor in 1943 and Professor in 1946. Brogden also served the University of Wisconsin from 1947 to 1958 as Assistant Dean and Associate Dean of its Graduate School. Wulf died on February 22, 1973, at the age of 60 in Madison, Wisconsin. He had had diabetes since the age of 20 , but he had dealt with this condition and subsequent illnesses and trauma with characteristic patience and self-discipline, so that he was able to enjoy a full, productive personal and professional life. In the end, a number of maladies, each potentially fatal, combined to overcome his unusual vitality and terminated the career of one of our outstanding experimental psychologists. Wulf was survived by his wife, Elinor Davis Brogden, his two daughters, Penelope Joel (Mrs. Stuart R. Grover) and Anne Abigail, and his two younger brothers, Professor 
Hubert Edward Brogden of Purdue University and Douglas Edward Brogden, Director of City Planning in Lincoln, Nebraska.

\section{SOME DETAILS}

It is impossible to "pigeonhole" Brogden as an adherent of any of the various controversial scientific positions that characterized American psychology during his career. He was thoroughly familiar with theoretical developnients during these years, but he was generally critical of their ultimate usefulness, so that his own research and the research that he directed was almost always aimed at resolving a scientific problem rather than testing a scientific theory. What he did was to think rigorously about his research findings and to try to express results in terms of detailed scientific laws that related concrete experimental operations to obtained results. In short, he reasoned close to his experimental manipulations and to his data.

Because of the sheer number, the astounding variety, and the high quality of his accomplishments, it is impossible to summarize them in a short paper, let alone to do them justice. What I shall try to do is to illuminate the personal and professional character of the man by expariding on some of the details of four aspects of his professional and personal life.

\section{The Years at the University of Illinois with Elmer Culler}

First. I want to talk about Brogden's years with Culler at the University of Illinois, At Illinois, while obtaining his $\mathrm{PhD}$, Wulf built the foundations and some of the superstructure of his scientific career; he received radiation damage to his right foot which was to plague his later years; and he found time to court and wed Elinor, who was to sustain him personally and professionally for the rest of his days.

Culler's Animal Hearing Laboratory, his work, and that of his students deserve an extensive treatment, more extensive than can be permitted here. To me, the work of Culler and his students at the Animal Hearing Laboratory simply defies belief, but the record is there for the reading. The laboratory was launched in 1931 in a worn-out frame building which had formerly been a student rooming house. Dogs, cats, guinea pigs, and monkeys were added to the indigenous population of roaches and other fauna. In the absence of antibiotics, the laboratory animals were nevertheless made to survive. In spite of the filthy conditions, aseptic surgery was performed on them and a vigorous, pioneering research program was carried out. Under these conditions, in the course of his contribution to this work, Brogden was to develop his scientific abilities.

During 1931-32, Culler and his first two research assistants, Glen Finch and Edward Girden, plus Fred Mettler, who joined them during summers, transformed the old rooming house into a scientific laboratory. Brogden joined the group in February 1933 and quickly became a full partner in the enterprise. Culler was intellectually generous and believed in an "open market place" of ideas. Wulf quickly gained the acceptance and respect of his older colleagues by virtue of the quality of his contributions to the daily give and take with Elmer, Ed, Glen, and Fred.

Now, to be able to carry out the research on animal hearing, for which the laboratory was founded, the first order of business had to be to develop effective methods of obtaining precise acoustic thresholds from the animal subjects. This was a major scientific undertaking in itself, for although Culler was an excellent psychophysicist, neither he nor his students yet knew much about animal conditioning. In a sense, the work on conditioning the forelimb flexion of the dog may be considered applied or methodological research, because it involved development of a method to be used for other purposes. In solving their conditioning problems, the Culler group achieved many scientific "firsts." This phase of the work of the laboratory beautifully illustrates how good applied science requires a sound foundation of pure and theoretical science. Extremely difficult and subtle problems, involving motivation and incentive as well as conditioning and learning, proved to be tractable to Culler's team, and Brogden played a major role in what was accomplished.

Consider two of the problems that were posed in obtaining hearing thresholds from animals. Quoting Culler, Finch, Girden, and Brogden (1935): (1) "Overactivity is a persistent and sometimes baffling problem ... even good animals may become nervous under the strain of repeated, intent listening for tones which are just barely discriminable from silence. They may begin reacting to their own body-noises or other minimal cues. Human subjects, as well, under the exacting conditions of limen-examination, now and then lapse into these random, confused responses" (Culler et al., 1935, p. 225). (2) "Reinforcement is clearly a fundamental problem. If the animal is never shocked at liminal intensities he will eventually fail to react to them; whereas if shocked on tones which he cannot hear, he becomes excited and overactive. When shall we shock him and when shall we not?" (Culler et al., 1935, p. 226). The fundamental, then novel, principles of "substitute reinforcement (buzzer substituted for electric shock)," intermittent shock reinforcement at threshold, and other methods were used to obviate these and other problems. The resulting procedures made it possible to "derive limens whose precision equals that of competent human subjects" (Culler et al., 1935, p. 227).

In spite of the success of the flexion conditioning technique in measuring the auditory acuity of dogs, the method could not be made to work with cats, rats, 
or guinea pigs. But as Girden writes (personal communiation) "A three-year problem of how to readily condition cats was cutely solved by Wulf with the rotary cage" (Brogden \& Culler, 1936). Adapted from the ordinary rotating activity cage, the device was so constructed that turning the cage 1 in. in either direction when the conditioned stimulus occurred would permit escape from or avoidance of the shock. Not only did the device work beautifully in conditioning cats, rats, and guinea pigs, but cats, for example, gave limens whose standard errors were less than $1 \mathrm{~dB}$ ! Furthermore, "these limens measured directly after the initial 50 trials are as consistent (low standard errors) as are the scores of representative dogs after weeks or even months of training" (Brogden \& Culler, 1936, p. 2). The laboratory performance of different species of animals, whether it involves simple learning, problem solving, or measurement of sensory acuity, depends greatly on the cleverness of the investigator in discovering a method which is suited to the animal's sensory and behavioral repertoire. Development of the rotating cage technique exemplifies such ingenuity. The cage worked because, as Brogden and Culler pointed out, "(1) It employs the shock incentive, which unlike food, is stable and unfailing, even when the animal's economy is greatly disturbed (newly operated, sick, decorticate)," “(2) The activity required of the animal is easy and familiar. Instead of localized differential response (retraction of the right fore-paw) any gross somatic behavior will do. The cage turns so readily as to require minimal incentive or energy." "(3) It gives the animal unhampered freedom of limb movement and thus obviates fighting the apparatus. Any form of restraint is particularly resented by cats." "(4) Its principal feature is probably that no response is incorrect. With most devices, everything the animal may spontaneously do is wrong except the one reaction imposed by the experimenter; hence, most of the training time is consumed in extinguishing or inhibiting false starts. Here, on the contrary, any movement gross enough to turn the cage is adequate. If the animal tries to escape it also turns the cage; whether it walks forward, backward, or sidewise is inmaterial. Only inactivity is unacceptable" (p. 304).

With the rotating cage now at their disposal, Brogden and his colleagues carried out a number of important experiments which have become classics. Probably the most frequently cited paper was "Role of incentive in conditioning and extinction" (Brogden, Lipman, \& Culler, 1938). The paper described four experiments on acquisition and extinction of CRs in guinea pigs and dogs. Culler had repeatedly emphasized that "the US plays a dual role; it determines the character or pattern of the CR and it provides the energy or drive needed to actuate the response pattern" (p. 109). These experiments dealt with the second role of the US. The first experiment compared CRs of guinea pigs that were conditioned with avoidable shock with CRs conditioned with unavoidable shock, and the investigator's conclusions have frequently been cited as stating that avoidable shock produced "better" conditioning than did unavoidable shock. In fact, the authors concluded that "how and when the incentive is applied determine the rate and character of resultant conditioning. Every stimulus asks a question or sets a task; and the CR which emerges constitutes the organism's reply to that question. One group finds a solution by turning the cage; the other group faced with unavoidable shock so places and tenses the trunk and limbs as to minimize its effect. The functional significance of the CR is crucial in deciding what form it should assume; and this significance is itself altered when the incentive is differentially applied" (p. 111). In no way does the foregoing constitute a statement that more, better, or faster conditioning is obtained with avoidable shock than with unavoidable shock.

One cannot even mention all eight of Brogden's papers which resulted' from his work in the animal hearing laboratory, but "Acoustic value of the several components of the auditory system in cats" (Brogden, Girden, Mettler, \& Culler, 1936) is an excellent example of the precision of the auditory work that was made possible by the newly developed techniques of threshold determination. In this investigation, hearing losses were determined following destruction of all combinations of right or left cochlea and right or left acoustic cortex in two-stage surgery conducted so that the relative contribution to hearing of the crossed and uncrossed fibers of the lateral lemniscus could be compared. The rise in thresholds for different subjects given the same surgery was nearly identical, many with standard errors less than $1 \mathrm{~dB}$. Destruction of one cortical hemisphere or one cochlea produced essentially identical hearing losses of 3 to $5 \mathrm{~dB}$, as would be the case with human subjects.

Adding the destruction of one cortex, ipsilateral or contralateral, to a destroyed cochlea produced additional hearing losses of 13 to $15 \mathrm{~dB}$, so that the authors concluded that the crossed and uncrossed fibers of the lemniscus were of equal acoustic significance. In view of the considerable differences in number of crossed and uncrossed fibers, this last finding was remarkable, but it confirmed earlier results with dogs (Mettler, Finch, Girden, \& Culler, 1934) which, when published, had been greeted with a measure of skepticism.

By the time Wulf received his $\mathrm{PhD}$ and left Illinois to work in Gantt's laboratory, he had taught himself much, had learned much from Elmer Culler and his co-workers, and had already accomplished much. Culler, who at times could be quite difficult, probably because of incipient Parkinson's disease, was a demanding task master, but a kindly man as well as an extremely rigorous and able one. Wulf was always 
to remember Elmer with affection and respect. Culler's cautious scientific style, his demands for "finished work with few loose ends" (Brogden, 1962, p. 156), his continual testing of ideas in the informal give and take at the laboratory, and his willingness to tackle very difficult scientific problems all left their mark on Brogden, who was well prepared to develop further with the facilities and the virtually complete independence accorded him by the generous and courtly Gantt.

\section{The Teacher}

Brogden was a fine teacher. $\mathrm{He}$ was widely knowledgeable and he was accurate, and he held himself and his students to a very high standard of performance. Wulf was at his best with graduate research and seminar students, but his basic attitude towards teaching and learning was bound to disconcert many undergraduates. Briefly, his conception of the responsibility of the teacher was to provide conditions and stimulation that would make the student, graduate or undergraduate, learn, organize, and think critically. Many of his and his colleagues' graduate students benefited greatly from his Seminar in General Psychology. His policy in the seminar was to ask the student to pick any topic in experimental psychology with which he was not familiar and to write a critical review of the literature on that topic. This paper was subject to intense criticism and argument, which ultimately produced papers of high quality.

In spite of his heavy administrative responsibilities, Wulf was almost always available and totally available to students, giving full attention and sustained interest for discussions respecting research and seminar work. These discussions were rewarding for all able and well-prepared students. On many occasions, when the student was not forthcoming with reasoned argument and relevant facts, Wulf would utilize an interesting technique. He would assume an outrageous theoretical position and defend it vigorously. If the student then argued cogently against the position, all went well. If, however, the student agreed with the ideas Wulf had expressed, their further critical discussion and Wulf's tenacious questioning were such as to make the unwary student realize that he had fallen into a trap. Usually, this painful insight led to better preparation and more careful thinking for their next and future meetings. Whenever Wulf quizzed a student orally, he was courteous but grave and formal, so that the student obtained few clues as to Wulf's reaction to his answers. Such clues as Wulf did give appeared in the subsequent lines of questions. I recall Wulf smiling only once during his interrogation of a student on a $\mathrm{PhD}$ oral examination. In this instance, the student. knowing Wulf quite well, was very cautious so as to avoid entangling himself. Finally, Wulf attributed a rather injudicious statement to the student. The student replied, "I said no such thing! What do you think I am, a vacuum cleaner salesman?" At this point, Wulf permitted himself to smile and proceeded to introduce another topic. Although Wulf was firm and formal with our students, he was kind and helpful when they faced technical or professional problems, and he was warm and sympathetic with them when they faced illness and other personal difficulties. Also, our students.very much enjoyed the fact that Wulf held his seminar in his own home. Here his wife, Elinor, provided coffee and other refreshments and contributed to the atmosphere of warm hospitality which complemented the essentially serious character of the seminar.

In 1972, 11 of Wulf's PhDs honored him with a volume of research papers, "Topics in Learning and Performance." The editors, Richard F. Thompson and James F. Voss, penned a tribute to Professor Brogden, which deserves quotation.

The term rigorous scientist may be regarded as a cliché, but those who have worked with Professor Brogden have been exposed not to these words but to a model who epitomized these traits. As one of the country's leading experimental psychologists, Professor Brogden's training of students was concerned not only with the importance of initiating, developing, conducting, and communicating significant experimentation, but also with the crucial significance of proper controls. Indeed, the topics discussed in this colume do not reflect a particular theoretical viewpoint or even a limited content area; instead, the common denominator of the individuals trained by Professor Brogden is their appreciation of the nature of sound experimentation in the areas of learning and performance.

In addition to his insistence upon properly designed, controlled, and analyzed experimentation, Professor Brogden not only encouraged but stressed the importance of independence in thesis and dissertation research. His emphasis upon the importance of independent thinking in scientific research is exemplified by his own research career, a career which clearly reflects an unusual generality of interest in a variety of topics, many of which he originated and pursued. Indeed, Professor Brogden's research career is characterized by the systematic and parametric investigation of a number of very significant problems irrespective of whether or not the particular issue was considered a "hot" topic of theoretical interest to other laboratories at the time. He recognized more than most scientists that scientific knowledge supercedes transient "fads."

While emphasizing independence in thesis and dissertation research, Professor Brogden has also believed in the equality of his collaborators. In research conferences between Professor Brogden and his students, ideas, designs and procedures were evaluated regardless of their source. In joint or multiple authorship, almost invariably the names of students occur first, with the names of more than one student occurring in alphabetical order. 
I believe that that tribute accurately epitomizes W. J. Brogden, the teacher. And the high quality of the postdoctoral research and scholarly achievements of Brogden's PhDs attests further to the quality of their mentor.

\section{The Administrator and the Policy Maker}

W. J. Brogden was the most generous academician I have ever known. He freely gave his time and his considerable talents to his students, to his departmental colleagues, to his university, particularly its graduate school, and to his nation. The total value of the product of these generous efforts was and remains great, but it is difficult to measure quantitatively. It is not really possible to estimate the cost of these efforts to Wulf's personal research productivity. In spite of any losses in research productivity that may have been caused by his administrative activities, his total bibliography (most of which appears in Topics in Learning and Performance) contains 85 items, a quite substantial number of quite substantial papers and chapters.

The quality of Wulf's administrative and policy making activity can be assessed in terms of what he accomplished in several roles. Wulf's first major administrative enterprise was directing research projects undertaken by the National Defense Research Committee during World War II. The scope and magnitude of these projects expanded progressively until they included selection and training of personnel and psychological factors in the design and operation of ground, sea, and airborne fire-control systems. Aside from the scope and complexity of the scientific problems involved in these research programs, the supervision of a considerable number of scientific, technical, and other personnel, plus the involvement of all three military services, and the required coordination with other research agencies, placed a substantial administrative burden on the director. How well did he do? Well, the Applied Psychology Panel (Bray, 1948, pp. 231-232) assessed the success of Brogden's military research projects as follows:

If the Army and Navy desire a complete research program they should give due consideration to wartime experience. In the case of the Applied Psychology Panel it was the opinion of the Panel staff that the project on lead-computing gunsights (see Chapter 6) might well be considered as a prototype for the organization of future research. The success of that project is worth analysis. The success revealed at least the following:

1. The existence of a real need for psychological study in new equipment.

2. That psychological research must be carefully organized under sympathetic supervision and established in the most effective time and place.

3. The caliber of assistance and the amount of time required from regular service officers. This included assistance in securing research facilities, diversion to the project of at least one preproduction model of each new device, participation in the work itself, and, particularly, active steps to insure application of results.

4. The need for education in technical subjects and the psychological training of the project staff.

5. That the research group should have prior experience in military research.

These characteristics of the organization of the project should be seriously considered in any postwar program.

For his war work, Brogden was later awarded a Presidential Certificate of Appreciation.

I was never intimately familiar with Wulf's administrative work in the Graduate School of the University of Wisconsin, but I have talked to people who worked with him and with students whose lives were affected by his decision. Wulf is remembered as a very decisive dean who could quickly give a "yes" or "no" answer with reasons to support it. In working out Graduate School policies, he was tenacious in reasoned argument. He was unwilling to bend regulations or change policies whenever academic values were threatened, and this trait made him Dean Elvehjem's favored "nay sayer" when an unpopular decision had to be conveyed to students or faculty.

I do know a great deal about Wulf's role in determining the policies of our Psychology Department. Five full-time equivalent faculty constituted the department in 1939, and the department grew to about 33 in 1970 . His wisdom in personnel selection and in promotion policies and actions made the department a strong one, and it would be hard to overestimate the importance of his role in bringing this about. Whenever Wulf had the responsibility of committee membership to bring in a recommendation on departmental policy, he was thoroughly prepared, had considered all the possibilities and their consequences, and he had considered the precedents that any particular decision or policy would set. In hammering out the final policy decision, Wulf expected his colleagues to be as thorough and thoughtful as he was himself, and he patiently tried to make us think. Sometimes he used the technique of the outrageous proposal or the outrageous argument to challenge us, so that to argue with him we had to think things through. My first impression in this connection was that Wulf was absolutely dead serious, because he never betrayed by facial expression or manner that he was otherwise. I concluded initially that he was a bit wild and also rigid. However, as I gained experience and understanding, my respect for his way of working with us increased greatly. I realized that I had to listen to his words carefully in order to understand completely that important issues might be involved in what I had 
initially considered to be a minor decision. In short, I discovered that there was truly "method in his madness."

Never was Wult's wisdom and foresight more decisive than in his negotiation of Korean War contracts between the University of Wisconsin and the U.S. Air Force and in his direction of the resulting projects, which were funded at about a quarter of a million dollars a year. When we tooled up for the contracts, about seven or eight of us went half-time on Air Force research, and we recruited 10 or 15 very able graduate students to assist. The transition into contract operations was smoothly accomplished under Wulf's guidance. More importantly, the transition out of contracting was smooth, and all academic values were protected. Wulf had foreseen the problems of the transition out of contracting and he had negotiated with the Dean of the College an agreement that a substantial portion of contract overhead funds would be held in a transition fund. When the contracts were finally ended rather abruptly, the graduate students involved were supported through to their PhDs on fellowships, and individual faculty members received one or two semesters of research leave, so that as the students came back after the war, faculty came back into full-time teaching and research. Anyone who wishes to contemplate the potential chaos in suddenly terminating a quarter-of-a-million-dollar operation in a small psychology department will appreciate Wulf's foresight and negotiating skill.

Finally, in his administration and policy making, Wulf was extremely creative. He was original; he viewed from different angles than other people; and he could smoothly accomplish a great deal with some very independent colleagues. Nowhere was this illustrated more beautifully than in the design of the Psychology Building at the University of Wisconsin. Wulf was Chairman of the department's Building Committee, and the first thing he did in this role was to seek suggestions from every departmental member as to his needs in the way of research and teaching facilities. Then other considerations entered into the mix. How large was the university going to grow? What different areas of psychology would be covered with a larger faculty? And so on. He worked smoothly with the architectural firm, whose representatives later were to say that the only building they would ever again undertake for the State of Wisconsin would be an extension of the University of Wisconsin Psychology Building, assuming that Professor Brogden would be Chairman of the Building Committee. He supervised the contracting so that specitications finally really met departmental needs. And finally, he was very careful and insistent in requiring that these specitications be met by the contractors. The department remains grateful for the efforts of this man in developing for us a very comfortable, effective research and teaching facility.
November 15, 1974, the building was rededicated as the W. J. Brogden Psychology Building, a fitting recognition of his role in the planning and construction of a very complicated, but functional, teaching and research structure.

\section{Wulf, The Person}

Personally, Wulf was a warm and kindly man. My personal impression was that the Brogden family was a close-knit and affectionate one. I also have the impression that Wulf was a firm parent and husband, but that his lovely wife and daughters found ways to get around him when this became necessary.

For most of his life, Wulf had been quite athletic and his preferred recreations reflect his physical abilities. He skied and played tennis; he loved camping in the West; and he loved to fish. (With respect to the fishing, I should comment that I believe that in developing the ability to catch countless trout on barbless hooks, he exercised the same skills that he had demonstrated in understanding the six species of animals on which he had experimented.) I loved to watch him fish, and I have never known a more intelligent fisherman. (The entire Grant family loved trout, and because the Brogdens did not have quite this much enthusiasm for fish, our family enjoyed the luxury of dining on as many trout as we could eat on our numerous family camping trips. I should add that, characteristically, Wulf, Elinor, Lucy, and I planned these camping trips with skill and care. The result was that although we were in tents, sleeping in bags, in primitive areas, often in inclement weather, we were more than comfortable and at times enjoyed a cuisine that could be described as luxurious. As indicated by the foregoing, Wulf was an enthusiastic outdoorsman. Another product of his interest in outdoor activity was the Brogden tree farm. Here he combined forestry skills, economic planning, and for him, a highly valued recreational activity. Wulf also loved to read detective stories and to play bridge and penny-ante poker. In poker, I doubt if Wulf had Hubert Brogden's technical skill, but he was an accomplished and wily player all the same. My impression is that Wulf preferred to win a poker hand by guile rather than by the cards themselves.

Just as Wulf was a truly outstanding scientist, he was also a truly outstanding person. I shall always have the fondest recollections of our close family relationships with the Brogdens. Parties, bridge, and poker sessions, camping together, all of these things certainly enriched my life. Our children were close personal friends, so close that the older ones mutually exercised the little tyrannies of childhood on the younger children of both families. How we felt about Wulf and Elinor is shown by the fact that in a joint will and testament my wife and I, with the Brogden's consent, asked that they be appointed the guardians of our minor children should they be orphaned. (The 
children reacted to this arrangement with ghoulish enthusiasm.)

With Wulf's death. the members of this Society-and experimental psychology in generalsuffered a great professional loss. For many of us. it is a great personal loss, but Wulf left us many substantial professional legacies. First of all, I should mention his distinguished PhDs, who learned much from Wulf and are passing this knowledge on to their students. Then there was the buildup of the University of Wisconsin Psychology Department and its research traditions. There was also the founding of the Psychonomic Society. And finally, we have, at the University of Wisconsin. the W. J. Brogden Psychology Building. so named by the Regents at the request of a grateful department fo commemorate one of its most valuable and distinguished members.

Wohltaten, still und rein gegeben, Sind Tote Die in Grabe leben-Goethe

\section{REFERENCES}

Brogden. W. J. Elmer Augustine Kurtz Culler: 1889-1961. American Journal of Psychology. 1962, 75. 155-160.

Brogden. W. J.. \& Culler. E. Device for motor conditioning of small animals. Science. 1936. 83. 269-270.

Clller, E., Finch. G., Girden. E., \& Brogden, W. Measurements of acuity by the conditioned-response technique. Journal of General Psichology. 1935. 12. 223-227.

Brogden. W. J.. Girden, E.. Mettler. F. A.. \& Culler, E. Acoustic value of the various components of the auditory system in cats. American Journal of Psychology, 1936. 116, $252-261$.

Mettler. F. A.. Finch, G., Girden, E., \& Culler, E. Acoustic value of the several components of the auditory pathway. Brain. 1934. 57. 475-482.

Thомpson. R. F.. \& Voss. J. F. (Eds.). Topics in learning and performance. New York and London: Academic Press. 1972. 